NBER WORKING PAPER SERIES

EXCHANGE-RATE MANAGEMENT VIEWED AS TAX POLICIES

Jacob A. Frenke1

Assaf Razin

Working Paper No. 2653

NATIONAL BUREAU OF ECONOMIC RESEARCH

1050 Massachusetts Avenue

Cambridge, MA 02138

July 1988

We are indebted to Thomas Krueger and Jonathan Ostry for helpful comments.

This paper draws on material contained in our book (Frenkel and Razin, 1987). The research reported here is part of NBER's research program in International Studies. Any opinions expressed are those of the authors not those of the National Bureau of Economic Research. 
NBER Working Paper \#2653

July 1988

\section{EXCHANGE-RATE MANAGEMENT VIEWED AS TAX POLICIES}

\section{ABSTRACT}

The paper develops an analytical framework which demonstrates that the various forms of exchange-rate management are equivalent to corresponding tax policies. To highlight the salient issues, we consider two specific categories of exchange-rate policies. The first is a dual exchange-rate regime, which separates exchange rates for commercial and for financial transactions, and the second is a unified exchange-rate system in which the couniry unilaterally pegs its exchange rate at the same rate for all transactions.

We show that the dual exchange rate policies can be usefully cast as distortionary taxes on international borrowing, and a unified pegged exchange-rate policies can be usefully cast as lump-sum tax cum subsidy policies. The equivalence between the various characteristics of exchange-rate management and tax management suggests that exchange-rate analysis could be usefully incorporated into the broader framework of the analysis of fiscal policies. A two-country model of the world economy is used to demonstrate the international transmission mechanism of these policies.

Jacob A. Frenke1

Research Department International Monetary Fund 70019 th street N.W. Washington, DC 20431
Assaf Razin

Department of Economics

Tel-Aviv University

Ramat-Aviv, Tel-Aviv 69978 Israel 


\section{Introduction}

This paper analyzes the problem of exchange-rate management from the perspective of tax policy. In general, monetary and fiscal policies are intimately related to each other through the budget constraint of the government. This interdependence implies that changes in the money supply arising from exchange-rate management necessitate corresponding compensating changes in monetary or tax policies designed to ensure public-sector solvency. In a frictionless undistorted model of the world economy, the specific combination of these monetary and tax policies is immaterial. In such a framework, the time distribution of lumpsum taxes and of monetary changes does not alter the real equilibrium. Such a model is characterized by Ricardian neutrality and the real equilibrium is neutral with respect to the nominal exchange-rate regime. If

In this paper, we modify the frictionless model by introducing key features that break the strong neutrality results. We consider a framework within which exchange-rate management exerts significant effects on the economic system. This framework is then used to demonstrate the equivalence of varlous policies of exchange-rate management and corresponding tax policies. It is for this reason that we view exchange-rate management as part of the broader issue of fiscal management.

To highlight the salient issues we consider two specific categories of exchange-rate policies. The first is a dual exchange regime, which separates exchange rates for commercial and for financial transactions.

1) For an analysis of such a model see Helpman and Razin (1979), He $\bar{l}$ pman (1981) and Lucas (1982). 
The second is a unified exchange-rate system in which a country unilaterally pegs its exchange rate at the same rate for all transactions.

The remainder of the paper is organized as follows. In Section II, we present the analytical framework. Section III analyzes the dual exchange rate regime from the perspective of distortionary taxes, while Section IV discusses the impact of the dual exchange rates on the world rate of interest. The analysis in the next two sections is concerned with the connection between the fixed (but unified) exchange rate system and lump sum taxes (Section $V$ ), and the effect of this regime on world interest rates (Section VI). Concluding remarks are presented in Section VII.

\section{The Analytical Framework}

In this section, we consider a minimal framework which nonetheless captures the main features necessary for the incorporation of monetary considerations. We assume a model in which domestic and foreign goods are internationally tradable and are perfect substitutes in consumption. For convenience we adopt the cash-in-advance formulation. If Accordingly, purchases of goods require cash payments which are assumed to be carried out in terms of the seller's currency. Thus, goods produced abroad are purchased with foreigr. currency, and domestically produced goods are purchased with domestic currency.

If For examples of such a formulation, see Lucas (1980), Stockman (1980), Helpman (1981), Greenwood (1983), and Persson (1984). 
At the beginning of each period individuals transact in the financial markets and obtain their desired portfolio composition. The desired holdings of domestic and foreign currencies reflect the pattern of planned purchases of domestic and foreign goods that take place during the period. The counterpart of these purchases are the sales of goods by firms. Accordingly, during each period domestic firms accumulate domestic currency and foreign firms accumulate foreign currency. At the end of each period (which coincides with the beginning of the subsequent period) domestic firms redistribute the proceeds of their sales to domestic individuals in the form of wages and dividends. Analogously, at the end of each period foreign firms also redistribute their proceeds to foreign individuals in the form of wages and dividends.

It is convenient to start with a specification of the policy actions undertaken in managing the dual (two-tier) exchange-rate regime. If In this context government transactions can be separated into two accounts: a domestic-currency account and a foreign-currency account. We assume that the government sets the paths of the two

1/ In general, the literature dealing with alternative specifications of the working of dual exchange-rate regimes view such regimes as instruments of balance of payments policies. For a recent analysis, see Dornbusch (1986).

Analyses of aspects of the relazions between taxes on capital flows, quantitative controls, and dual exchange rates are provided in Adams and Greenwood (1985), Greenwood and Kimbrough (1984), Obstfeld (1984), and Stockman and Hernandes (1985). For an analysis of dual exchange rates or capital controls in the context of public $f$ inance and distortionary taxes, see Aizenman (1986) and Persson and Svensson (1985) and $f$ or an analysis of dual exchange rates as a second-best policy, see Adams and Greenwood (1985). 
exchange rates (the commercial and the financial rates) and allows free mobility of capital.

In period the monetary expansion induced by government foreign exchange intervention in pegging the financial exchange $r a t e$ is $\bar{s}_{t}\left(\hat{B}_{t}^{p}-\tilde{R}_{F} \hat{B}_{t-1}^{p}\right)$, where $\bar{s}_{t}$ denotes the pegged financial exchange rate, $\tilde{R}_{F}$ denotes the world (fixed) nominal rate of interest on foreigncurrency denominated bonds, and $\hat{\mathrm{B}}^{\mathrm{P}}$ denotes private-sector debt expressed in units of foreign exchange. The monetary expansion in period $t$ associated with pegging the commercial exchange rate at the level $\bar{e}_{t}$ is $\bar{e}_{t} P_{t}^{*}\left(Y_{x}-C_{t}\right)$, where $\left(Y_{x}-C_{t}\right)$ is the (per-capita aggregate) real trade balance--the excess of production (which is assumed to be fixed) over spending. Thus, the monetary injections associated with foreign exchange interventions are:

$$
\tilde{x}_{t}=\bar{e}_{t} p_{t}^{*}\left(Y_{t}-C_{t}\right)+\bar{s}_{t}\left(\hat{B}_{t}^{p}-\tilde{R}_{F} \hat{B}_{t-1}^{p}\right) .
$$

It is noteworthy that in this formulation we have assumed for convenience that the exchange rate applicable to debt service is the financial exchange rate. The key results of the paper do not depend on this assumption.

An alternative specification generating a dual exchange-rate regime assumes that the government imposes a binding quota on the volume of private-sector net international borrowing and pegs the commercial exchange rate. In this formulation the financial exchange rate, $s$, is determined in the free market. We denote the quota by $\bar{B}_{t}^{p}$. Accordingly, equation (1) becomes: 
(2) $\quad \tilde{x}_{t}=\bar{e}_{t} p_{t}^{*}\left(Y_{x}-c_{t}\right)+s_{t}\left(\bar{B}_{t}^{p}-\tilde{R}_{F} B_{t-1}^{p}\right)$.

The two alternative formulations of the monetary consequences of exchange-rate interventions reflect themselves in the money supply. The money supply process is formulated as

$$
M_{t}=M_{t-1}+\tilde{x}_{t}-T_{t}
$$

where $M_{t}$ denotes period $t$ domestic money supply and $T_{t}$ denotes taxes.

Money-market equilibrium in the domestic economy impiles that

(4) $\quad P_{t} Y_{X}=M_{t}$

where $P_{t}$ and $Y_{X}$ denote the domestic-currency price of the good and the level of domestic output, respectively.

The left-hand side of equation (4) represents the (reduced-form) world demand for domestic currency. It represents the sum of the domestic demand, $M_{H t}$, and the foreign demand, $M_{H t}^{*}$. In view of the cash-inadvance constraints the sum of these demands can be written as $P_{t}\left(C_{x t}+C_{x t}^{*}\right)$, where $C_{x t}^{*}$ denotes the foreign purchase of the domestically produced good. The requirement that the world demand for the domestic good equals the level of domestic output implies that $C_{x t}+C_{x t}^{*}=Y_{x}$. Hence, $P_{t} Y_{x}$ is the world demand for the domestic currency. Equivalently, the interpretation of the left-hand side of equation (4) could also be given by noting that money is used only for transactions involving the purchase of domestic output; hence, if all output is purchased, the world demand for domestic money equals the value of domestic output. In equilibrium, this quantity equals the 
existing supply of money. In this context, we note in passing that in the simple formulation of equation (4), since money serves only as a medium of exchange, the income velocity of circulation is unitary.

The private sector is assumed to consist of overlapping generations as in Blanchard (1985) and Frenkel and Razin (1986a, 1986b). This assumption introduces into the model a finite expected horizon in which the probability of survival of each individual from each period to the next is denoted by $\gamma$. Accordingly, the budget constraint of an individual of age a time $t$ is:

$$
\bar{e}_{t} P_{t}^{*} c_{a, t}=\bar{e}_{t-1} P_{t-1}^{*} Y_{x}+s_{t} \hat{b}_{a, t}-\tilde{T}_{t}-\frac{\tilde{R}_{F}}{\gamma} s_{t} \hat{b}_{a-1}, t-1
$$

where $\hat{b}$ is the debt of the individual expressed in units of foreign currency. Accordingly, $\bar{e}_{t} P_{t-1}^{*} Y_{x}$ represents the sales by domestic firms during period $t-1$, whose proceeds are distributed to individuals at the beginning of period $t$. The last term on the right-hand side of equation (5) represents the debt commitments. As is evident, the relevant effective rate of interest is $\left(\tilde{R}_{F} / Y\right)-1$, reflecting the risk associated with mortality. The unique feature of the dual exchange-rate regime is reflected by the two exchange rates appearing in equation (5). The domestic price level, $P_{t}=\bar{e}_{t} p_{t}^{*}$, is governed by the commercial exchange rate through the purchasing-power-parity relation. On the other hand, debt commitments are settled using the financial exchange rate, $s_{t} \cdot 1 /$

1/ Strictly speaking, equation (5) applies to the formulation under which the financial exchange rate, $s_{t}$, is determined in the free market. With the alternative formulation, under which the path of the financial $t$ is replaced by $s^{t}$.

exchange rate is also pegged, the term $s$ 
Equation (5) is the budget constraint applicable to period $t$. It is shown in the Appendix that consolidating the periodic budget constraints into a single lifetime constraint and making use of the requirement that in the limit as time approaches infinity the present value of debt commitment (computed using the effective rate of interest) is zero yields:

$$
\text { (6) } \begin{aligned}
\sum_{t=0}^{\infty} \frac{\bar{e}_{t} P_{t}^{*}}{s_{t}} d_{t} c_{a+t, t} & =\sum_{t=0}^{\infty} \frac{\bar{e}_{t-1} P_{t-1}^{*}}{s_{t}} d_{t} Y_{x}-\sum_{t=0}^{\infty} d_{t} \frac{\bar{T}_{t}}{s_{t}}-\frac{\bar{R}_{F,-1}}{Y} b_{a-1,-1} \\
& =\hat{w}_{a, o}
\end{aligned}
$$

where $d_{t}=\left(Y / \bar{R}_{F}\right)^{t}$.

This constraint defines the initial value of wealth, $\hat{w}_{a, 0}$, expressed in units of first-period foreign currency. The economic interpretation of the various terms follows. Consider, for example, the coefficients of $c_{a, 0}$ and $c_{a+1,1}$ on the left-hand side of equation (6). These coefficients are $\bar{e}_{0} P_{O}^{*} / s_{0}$ and $\left(\bar{e}_{l} P_{l}^{*} / s_{l}\right)\left(Y / \bar{R}_{F}\right)$, respectively. The domestic relative price of consumption in period one in terms of consumption in period zero is $\left.\left[\left(\bar{e}_{1} / \bar{e}_{0}\right) /\left(s_{1} / s_{0}\right)\right]\left[P_{l}^{*} / P_{0}^{*}\right) /\left(\tilde{R}_{E} / Y\right)\right]$. This relative price is the product of two terms: the real effective world discount factor (shown by the second bracketed term) and the differential rates of depreciation of the commercial and the financial exchange rates (shown by the first bracketed term). This latter component, which represents the contribution of exchange-rate management to the overall real rate of return on investment in financial assets, translates the world real effective discount factor into the corresponding domestic discount factor. That is, the capital gain on an investment in assets 
denominated in foreign currency is $\left(s_{1} / s_{0}\right)$, and its product with $\left(\vec{e}_{0} \vec{e}_{1}\right)$ translates the return into units of foreign-currency-denominated goods. A similar interpretation applies to the coefficients multiplying the rates of consumption in other periods. As is evident, divergencies between the domestic and the foreign real rates of interest stem from the terms involving exchange-rate changes in the dual exchange-rate regime. It is important to note that these divergencies arise only from differences in the percentage rates of depreciations of the commercial and financial exchange rates. In the absence of such differences, the domestic and foreign real rates of interest are equalized.

The present-value factors multiplying the levels of output on the right-hand side of equation (6) differ from those used to evaluate the consumption sequence. The difference arises from the underlying cashin-advance formulation, according to which nominal proceeds from sales of output are distributed with a one period lag. The next term on the right-hand side of equation (6) represents the discounted sum of nominal taxes. The final term is the individual's debt commitment $\left(\tilde{R}_{F,-1} / Y\right) \hat{b}_{a-1,-1}$. To express these quantities in units of period-zero consumption, we need to multiply the various coefficients by $s_{0} / \bar{e}_{0} P_{0}^{*}$. As a result for any given initial foreign price, the real value of wealth also depends on the ratio of the two exchange rates in period zero, $s_{0} / \vec{e}_{0}$.

To evaluate the real effects of exchange-rate management, we need to determine the equilibrium value of wealth. The foregoing discussion dealt with the factors governing the pricing of consumption in various periods, under the conditions of a dual exchange-rate regime. To 
complete the analysis of the determinants of consumption, we need to determine the dependence of the equilibrium level of wealth on the exchange-rate regime. Accordingly, we substitute the equilibrium conditions into the individual equation (6) which is then aggregated over individuals. As shown in the Appendix, this procedure yields:

$$
\begin{aligned}
\hat{w}_{0} & =\sum_{t=0}^{\infty} \frac{\bar{e}_{t} P^{*}}{s_{t}} d_{t} Y_{x}+\sum_{t=0}^{\infty}\left(\frac{\bar{e}_{t}}{s_{t}}-\gamma \frac{\bar{e}_{t+1}}{s_{t+1}}\right) d_{t} \hat{B}_{t} \\
& -(1-\gamma) \sum_{t=0}^{\infty} d_{t} \hat{B}_{t}^{p}-\frac{\bar{e}_{0}}{s_{0}} \tilde{R}_{F,-1} \hat{B}_{-1},
\end{aligned}
$$

where $\hat{W}_{0}$ denotes the (per-capita) aggregate value of equilibrium wealth expressed in units of period-zero foreign exchange.

The pertinent characteristics of equation (7) are discussed in the subsequent sections. Prior to this discussion, it is relevant to remark that the pricing coefficients of output, $\left(\bar{e}_{t} p_{t}^{*} / s_{t}\right) d_{t}$, are the same as the pricing coefficients of consumption shown in equation ( 6 ). In equilibrium, the lagged payments reflecting the cash-in-advance convention have no effect on the pricing of outputs.

In interpreting the salient features of the equilibirum wealth given in equation (7), it is useful to consider a benchmark case in which the authorities do not intervene at all in the foreign exchange market and allow for free international mobility of capital. The analysis of this special case highlights the basic mechanisms through which exchange-rate management influences the economic system. Accordingly, in this case, $\bar{e}_{t}=s_{t}$, and $\hat{B}_{t}^{p}=\hat{B}_{t}$ (since in the absence of 
intervention and open-market operations public-sector debt is zero). Hence, equation ( 7 ) becomes:

$$
\hat{W}_{0}=\sum_{t=0}^{\infty} P_{t}^{*} d_{t} Y_{x}-\tilde{R}_{F,-1} \hat{B}_{-1} .
$$

In this benchmark case, therefore, the equilibrium value of wealth is the discounted sum of GDP net of initial external debt commitment. This expression reveals that the consumption-opportunity set is the same as the one obtained in the undistorted barter economy. This illustrates the point that the finiteness of the horizon, in and of itself, does not introduce a distortion into the economic system.

\section{Dual Exchange Rates as Distortionary Taxes}

In order to focus on the unique mechanism associated with the dual exchange-rate policies, consider the infinite-horizon case in which $\gamma=1$. To facilitate the exposition, we suppose that the foreign price is fixed and normalized to unity; that is, we let $P_{t}^{*}=1$. In that case $\tilde{R}_{F}=R$, and since $\gamma=1$, we replace the present-value factor $d_{t}$ by $\alpha_{t}=R^{-t}$. Further, we express equation (7) in units of firstperiod consumption--by multiplying each term by $\left(s_{0} / \bar{e}_{0}\right)$--and note that the real value of wealth spans the consumption-opportunity set. AccordIngly,

$$
\begin{aligned}
t_{t=0}^{\infty} \pi_{t} \alpha_{t} C_{t} & =\sum_{t=0}^{\infty} \pi_{t} a_{t} Y_{x}+t \stackrel{\infty}{\Sigma}=0_{0}\left(\pi_{t}-\pi_{t+1}\right) B_{t}-R_{-1} B_{-1} \\
& =w_{0},
\end{aligned}
$$

where $\pi_{t}=\left(s_{0} / \bar{e}_{0}\right) /\left(s_{t} / \bar{e}_{t}\right)$. 
We define the dual exchange-rate premium by the percentage discrepancy between $s$ and $\bar{e}$; that is, the premium is $(s / \bar{e})-1$. Accordingly, $\pi_{t}$ reflects the evolution of the dual exchange-rate premium over time. A rise in the premium is associated with a decline in $\pi_{t}$. The discounted sum of consumption shown in equation (9) differs from the one obtained in the undistorted Ricardian model by one important property: it is influenced by the time path of the dual exchange-rate premium. Indeed, if the premium is constant for all time, then the consumptionpossibility set characterized by equation (9) coincides with the one obtained in the undistorted barter economy.

In general, the evolution (rather than the level) of the dual exchange-rate premium influences the consumption-possibility set by distorting the prices governing the intertemporal allocation of consumption (and of output if investment is allowed for) and by influencing wealth. The distortionary ef fect on the intertemporal prices arises from the wedge that the dual exchange-rate system introduces between the effective domestic and world rates of interest. An additional channel through which the dual exchange-rate premium influences wealth operates through the interaction between the evolutions of the premium and of the external debt, as reflected by the term

$$
\sum_{t=0}^{\infty} \alpha_{t}\left(\pi_{t}-\pi_{t+1}\right) B_{t} .
$$

To illustrate this mechanism, consider, for example, the coefficient of $\mathrm{B}_{0},\left\{1-\left[\left(\mathrm{s}_{0} / \bar{e}_{0}\right) /\left(\mathrm{s}_{1} / \bar{e}_{1}\right)\right]\right\}$. With positive net external debt, $B_{0}$, this coefficient represents the "subsidy rate" induced by the evolution of the premium, and $B_{0}$ is the "subsidy base." The subsidy rate 
represents the percentage rate of reduction in the value of the debt measured in terms of domestic goods. Accordingly, if $s_{1}$ exceeds $s_{0}$, then the foreign-currency value of the debt incurred in period zero depreciates. Adjusting this depreciation for the rise in domestic prices (indicated by $\bar{e}_{1} / \bar{e}_{0}$ ) yields the subsidy in real terms. Accordingly, the expression in equation (10) can be viewed as the discounted sum of the products of the periodic subsidy rates and the periodic subsidy bases.

The two effects of the dual exchange-rate system (the intertemporal-price effect and the wealth effect) are equivalent to those arising from the imposition of distortionary taxes on international borrowing. Since in our formulation the exchange rate applicable to debt service is the financial rate, this dual exchange-rate system is equivalent to a system of taxes on international borrowing in which debt service is not exempt from the tax. Alternatively, a dual exchange-rate system, in which the exchange rate applicable to the debt service is the commercial rate, is equivalent to the system of taxes on international borrowing in which debt service is exempt from the tax.

We conclude this section by characterizing the effects of dual exchange-rate policy, cast as a distortionary tax on international borrowing, on the real equilibrlum of a small open economy. Assuming a logarfthmic utility function--so that the consumption function is $c_{t}=(1-\delta) W_{t}$ (where $\delta$ denotes the subjective rate of discount)--and recalling that from the national income accounts that $C_{t}-Y_{t}=B_{t}-R B_{t-1}$, we can solve for the time path of external debt. Accordingly, 
(11) $\quad B_{t}=\frac{C_{0}}{a_{t}} \sum_{\tau=0}^{t} \frac{\delta^{\tau}}{\pi_{\tau}}-\sum_{\tau=0}^{t} \frac{Y x}{a_{t-\tau}}+\frac{R_{-1}{ }-1}{a_{t}}$.

Equation (11) states that the economy's external debt is the difference between the sum of the present values of past (and present) consumption and outputs adfusted for the initial debt commitment (in present value as of period $t$ ).

Using the economy-wide solvency requirement that in the limit (as time goes to infinity) the present value of external debt (evaluated by using the world real rate of interest) equals zero, equation (11) can be written as:

$$
C_{0}=\frac{\sum_{t=0}^{\infty} \pi_{t} a_{t} y_{x}-R_{-1}^{B}-1}{\sum_{t=0}^{\infty}\left(\delta / \pi_{t}\right)} .
$$

Equation (12) shows that a future deceleration in the rate of change of the dual exchange-rate premia (i.e., a rise in $\pi_{t}$ ) raises current consumption. This rise reflects the increased value of wealth consequent on the reduction in the effective domestic rate of interest.

Equations (11) and (12) constitute a system that can be solved to yield the equilibrium path of the external debt and the equilibrium value of $c_{0}$ for the case in which the dual exchange-rate regime is implemented through pegging the exchange-rate premium, thereby determining the path of $\pi_{t}$. Alternatively, if the dual exchange-rate regime is implemented through the imposition of a binding quota on the private sector's external borrowing, then the same system of equations (together with the specification of the path of government debt) can be solved for the path of the dual exchange-rate premium and for the equilibrium value of consumption. 


\section{Effects of Dual Exchange-Rate Policies on the World Rate of Interest}

We develop now a simple diagrammatic exposition that is useful for the analysis of the international effects of a dual exchange in a twocountry model of the world economy. The diagrammatic aparatus is developed in detail in Frenkel and Razin (1987, 1988). The key channel through which the effects of the dual exchange-rate policies are transmitted internationally is via changes in the world rate of interest. To facilitate the exposition, we divide the horizon into two periods: the present, which is denoted by $t=0$, and the future $(t=1,2, \ldots)$, and use the aggregation procedure outlined in Frenkel and Razin (1986b). To apply this procedure of aggregating quantities pertaining to all future periods into a composite single quantity we need to compute the present values of various flows. Assuming that output and the dual exchangerate premium do not vary across future periods $(t=1,2, \ldots)$, we define a constancy equivalent (average) interest rate $r$ and the corresponding market discount fact or $R=1+r$. For ease of exposition, we also abstract from mortality risk and assume that $\gamma=1$.

Under these assumptions, the private-sector budget constraint (equation (9)) can be modified to yield:

$$
C_{0}+\frac{\pi}{R(R-1)} C=Y_{x 0}+Y_{X}\left(\frac{\pi}{R}+\frac{1}{R(R-1)}\right)+(1-\pi) B_{0}-R_{-1} B_{-1}
$$

where $C$ is the average consumption $(t=1,2, \ldots)$ and where we recall that $R=1+r$ and $\pi=\left(s_{0} / \bar{e}_{0}\right) /\left(s_{1} / \bar{e}_{1}\right)$. Finally, in order to focus on the domestic country's dual exchange-rate policies we assume that the 
foreign country adopts a flexible exchange-rate system and thus its private-sect or budget constraint is:

$$
C_{0}^{*}+\frac{1}{R(R-1)} C^{*}=Y_{m 0}^{*}+\frac{Y_{m}^{*}}{R-1}+R_{-1} B_{-1},
$$

where variables pertaining to the foreign economy are denoted by an asterisk; $Y_{m}^{*}$ denotes foreign output and the domestic initial debt, $B_{-1}$, is equal to foreign initial assets. The assumption of a unified world capital market implies that the market discount factor, $R$, is common to both countries.

The analysis is conducted with the aid of Figure 1 , in which the downward sloping schedules plot the desired ratio of current to future consumption as a decreasing function of the average rate of interest. The assumption that the utility functions are nomothetic enables us to express the various demand schedules in terms of desired consumption ratios. The domestic and the foreign private-sector relative demands are denoted by $D$ and $D^{*}$, and their values at the point in which $\left(C_{0} / C\right)=\left(C_{0}^{*} / C^{*}\right)=1$ indicate, respectively, the domestic and foreign subjective rates of time preference $\delta$ and $\delta^{*}$. The elasticities of the relative demand schedules are the corresponding intertemporal elasticities of substitution. The world relative demand, $D^{W}$, is the weighted average of the two private sectors' relative demands, $D$ and $D^{*}$. That is:

$$
\frac{c_{0}+c_{0}^{*}}{c+c^{*}}=\mu \frac{c_{0}}{c}+(1-\mu) \frac{c_{0}^{*}}{c^{*}}
$$

where 
FIGURE 1

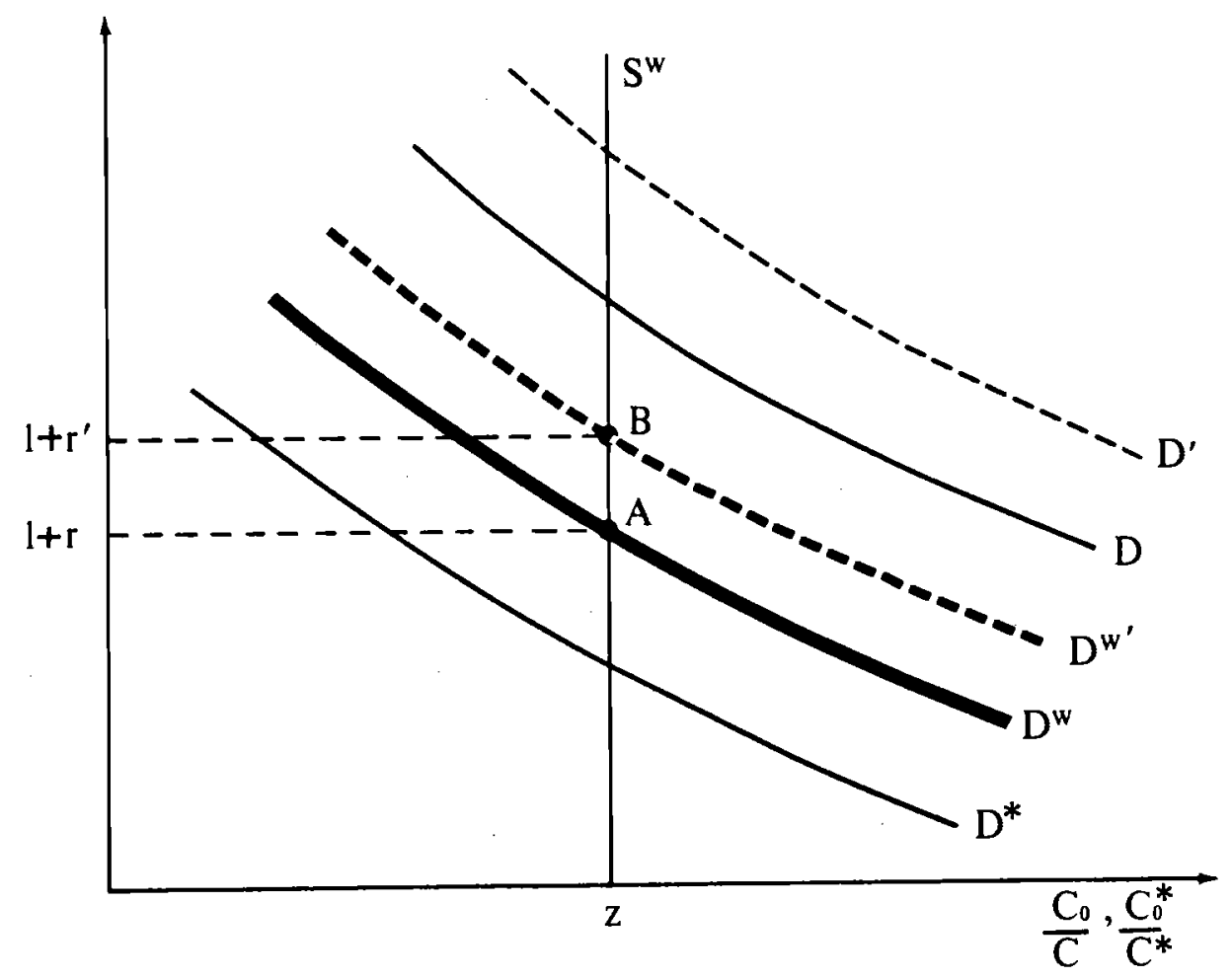


$\mu=\frac{c}{c+c^{*}}$.

The vertical schedule, $s^{w}$, describes the ratio, $z$, of current to future world GDP.

$$
z=\frac{Y_{x 0}+Y_{m 0}^{*}}{Y_{X}+Y_{m}^{*}}
$$

The initial equilibrium, in which both countries adapt the flexible exchange rate system, is described by point $A$.

The introduction of a dual exchange-rate system by the domestic goverment changes the positions of the domestic relative denand curve D. The direction of the change depends on the implied path of the real exchange rate premium $\pi=\left(s_{0} / \bar{e}_{0}\right) /\left(s_{1} / \vec{e}_{1}\right)$. If $\pi>1$, then the policy raises the effective price of future consumption and induces a substitution toward current consumption. Thus, for each and every value of the world rate of interest, the domestic relative demand schedule shifts to the right from $D$ to $D^{\prime}$. The vertical displacement of the schedule is proportional to the change in the path of the dual-exchange rate premium $\pi$. Associated with the new domestic relative demand, the new world relative demand (the weighted average of domestic and foreign relative demands) also shifts to the right from $D^{W}$ to $D^{W^{\prime}}$, and its proportional rightward shift is equal to the domestic-country weight $\mu$ times the percentage rightward displacement of the $D$ schedule. The new equ1librium obtains at point $B$, at which the world rate of interest rises.

A similar analysis could show that if $\pi<1$, then the policy lowers the effective price of future consumption and induces a substitution 
toward future consumption. Under such circumstances, the world rate of interest falls.

\section{Exchange Rate Management as Lump-Sum Taxes}

In this section we depart from the bench-mark case of equation (8) and examine the pure wealth effects of exchange-rate management. Thereby we determine the circumstances under which exchange-rate policies can be shown to be equivalent to lump-sum tax policies. In order to focus on the pure wealth effect associated with exchange-rate management, we introduce again the finite horizon by assuming that the value of $\gamma$ is less than unity, and we assume that the authorities peg the exchange rate without separating between the commercial and the financial rates. In such a unified exchange rate regime, the management of the rate is nondistortionary, and its impact on the real economic system operates only through the pure wealth effect (see Helpman and Razin (1987) for a similar framework).

Using the assumptions that the exchange-rate regime is unified (i.e., $e_{t}=s_{t}$ ) and that the fixed foreign price $P^{*}$ is normalized to unity, we express the consumption-opportunity set of equation (7) as:

$$
\sum_{t=0}^{\infty} d_{t} C_{t}={ }_{t=0}^{\infty} d_{t} Y_{x}+(1-\gamma) \sum_{t=0}^{\infty} d_{t} B_{t}^{8}-R_{-1} B_{-1}
$$

where we have used the definitions of $B^{B}=B-B^{p}$ and $d_{t}=(Y / R)^{t}$.

The only element that distinguishes between the consumption-opportunity set shown in equation (16) and the set obtained in the barter economy (embodied in the expression for wealth in equation (8)) is the second term on the right-hand side of equation (16). It follows that in 
contrast with the consequences of dual exchange rates, the unified rate results in undistorted intertemporal prices. For example, as shown on the left-hand side of equation (16), the relative price of consumption in period 1 in terms of consumption in period 0 is the world real discount factor, $1 / \mathrm{R}$.

In our pure monetary model without government spending, the term $(1-\gamma) \Sigma_{t=0}^{\infty} d_{t} B_{t}^{B}$ is governed by the movement of international reserves induced by the pegging of the exchange rate. Accordingly, unless the government designs its tax and monetary policy so as to always meet (at the given peg) changes in the demand for money, the pegging operations are reflected in the evolution of government debt.

As is evident, changes in the stock of government debt influence the real equilibrium by altering the value of wealth. The extent to which government debt influences private-sector wealth depends on the difference between private and social rates of discount. This difference reflects the finiteness of the individual's expected horizon and it is the same mechanism responsible for the real effects of lump-sum taxes analyzed in Frenkel and Razin (1986a). Thus, the effects of unified exchange-rate management are equivalent to those exerted by lump-sum tax cum transfer policies.

\section{Effects of a Unifled Pegged Exchange Rate on the World Rate of Interest}

World equilibrium requires that in each period the given supply of world output equals the demand. To facilitate the exposition, we again divide the horizon into two periods: the present, which is denoted by $t=0$ and the future which consolidates all periods from $t=1$ forward. 
The exposition in this section is based on the assumption that the utility function is logarithmic. Under this assumption, the marginal propensity to save is $\gamma \delta$ (where $\gamma$ denotes the survival probability and $\delta$ denotes the subjective discount factor). Accordingly, as shown in Frenkel and Razin (1986b), the per-capita aggregate consumption function is:

$$
c_{t}=(1-\gamma \delta) w_{t},
$$

where per-capita aggregate wealth, $W_{t}$, equals the sum of human wealth and financial wealth. Human wealth is the discounted sum of disposable income, computed by using the effective rates of interest. It is assumed that the foreign and dornestic consumption functions have a similar form.

The equilibrium conditions include the specification of the initial values of domestic and foreign wealth as well as the requirement that present and future goods-markets clear. These conditions are given in equation (18) through (2I).

(18) $\quad W_{0}=\left(Y_{X_{0}}+B_{0}^{g}\right)+\frac{Y}{R-\gamma}\left(Y_{X}-T\right)$

$$
+\left(1+r_{-1}\right)\left(B_{-1}^{8}-B_{-1}\right) \text {, }
$$

$$
\begin{aligned}
& W_{0}^{*}=\left(Y_{m 0}^{*}-T_{0}^{*}\right)+\frac{Y}{R-Y}\left(Y_{m}^{*}-T^{*}\right) \\
&+\left(1+r_{-1}\right)\left(B_{-1}^{B}+B_{-1}\right), \\
&(1-Y \delta) W_{0}+\left(1-Y \delta^{*}\right) W_{0}^{*}=Y_{X 0}+Y_{m 0}^{*}
\end{aligned}
$$


(21)

$$
\begin{aligned}
{\left[Y \delta W_{0}\right.} & \left.+\frac{(1-Y)}{(R-1)} \frac{R}{(R-Y)}\left(Y_{X}-T\right)\right] \\
& +\left[Y \delta^{*} W_{0}^{*}+\frac{(1-Y)}{(R-1)} \frac{R-Y)}{\left.\left(R-Y_{m}^{*}-T^{*}\right)\right]}\right. \\
& =\frac{1}{R-1}\left(Y_{X}+Y_{m}^{*}\right)
\end{aligned}
$$

where we have assumed that $\gamma=\gamma^{*}$.

Equations (18) and (19) specify the initial equilibrium values of domestic and foreign wealth owned by the existing population. In this specification, private wealth is expressed as the sum of the present values of current and future disposable incomes plus the net asset positions. In these equations, the term $Y /(R-Y)$ denotes the present value of an annuity (commencing at period $t=1$ ) evaluated by using the effective constancy-equivalent interest rate. A unique feature of equation (18) is the inclusion in 1 t of the term $B_{0}^{8}$. This term, which equals the amount of short-term government debt (reserve losses) associated with the exchange-rate management, reflects the capital gains (due to overvalued currency) captured by the currently alive domestic private sector (see Helpman and Razin (1986)). These equations also embody the requirement that the home country's initial external indebtedness, $B_{-1}$ equals the foreign country's initial net creditor position.

Equation (20) is the requirement that world demand for goods in period $t=0$ equal world supply. The left-hand side of this equation shows the sum of domestic and foreign per-capita private sector's consumption (as implied by equation (17) and its foreign counterpart), and the right-hand side is the sum of per-capita domestic and foreign outputs $\left(Y_{x O}\right.$ and $\left.Y_{m 0}^{*}\right)$ net of government spending. The equality between 
$Y$ and $\gamma^{*}$ ensures that the sizes of the population of the two countries are equal to each other. As a result, aggregate world demand and supply can be expressed in terms of an equality between the unweighted sum of the individual country per-capita demand and the unweighted sum of the corresponding per-capita supply.

Equation (21) specifies the requirement that the discounted sum of per-capita domestic and foreign private demand for future goods equal the discounted sum of per-capita future world outputs net of government spending. These discounted sums are computed as of period $t=0$ with the aid of the constancy equivalent (average) interest rate. The interpretation of the various terms follows. Consider the first bracketed term on the left-hand side of equation (20). In this expression, the term $\gamma \delta W_{0}$ represents the per-capita savings of the population present in $t=0$; these savings ultimately must be spent on future goods. The second term represents the per-capita wealth of those who will be born in all future periods from $t=1$ onward; this wealth will be spent on future goods. To verify that this is indeed the meaning of the second term, we note that $\left(Y_{X}-T\right)$ is the disposable income of each individual at the time of birth and its product with $R /(R-\gamma)$ is the present value of such an annuity. Therefore, the term $[R /(R-Y)]\left(Y_{X}-T\right)$ denotes each individual's wealth at the time of birth, and since by our normalization the size of each cohort at birth is one individual, this term also represents the cohort's wealth at birth. Since in each period in the future there is a new cohort whose wealth at birth is computed similarly, the discounted sum of all future cohorts' wealth (as of period $t=1$ ) is obtained by multiplying the term $[R /(R-Y)]\left(Y_{X}-T\right]$ by $R /(R-1)$, which denotes the 
present value of an annuity (commencing at $t=1$ ) evaluated by using the risk free interest rate. The resulting expression is then discounted to the present (period $t=0$ ) through a division by $R$. This yields $[R /(R-I)(R-Y)]\left(Y_{X}-T\right)$. Multiplying this term by $(1-Y)$ converts this aggregate wealth into the corresponding per-capita wealth. A similar interpretation applies to the second bracketed term on the left-hand side of equation (20). Finally, the right-hand side of equation (20) is the discounted sum of all future domestic and foreign outputs net of governments' spending. As a manifestation of Walras' 1 aw, the system (18) through (20) is linearly dependent.

In addition to equations (17) through (20), the equilibrium conditions also include the requirements that both governments be solvent. Expressed in terms of the average interest rate, and assuming domestic government solvency, the domestic government constraint is:

$$
B_{0}^{B}=-\frac{1}{R-1} T
$$

Using the government budget constraint, substituting $\mathrm{C}_{0} /\left(1-\mathrm{Y}_{\delta}\right)$ for $\mathrm{W}_{0}$ ' and omitting equation (18) by Walras' law, the complete system of equations can be reduced to two basic market-clearing equilibrium conditions, one for present goods and another for future goods. These conditions are:

$$
\begin{aligned}
C_{0} & +\left(1-\gamma \delta^{*}\right)\left[Y_{m 0}^{*}+\frac{\gamma}{R-Y}\left(Y_{m}^{*}-T^{*}\right)\right. \\
& +\frac{1}{R-1}\left(T^{*}+\left(1+r_{-1}\right) B_{-1}\right]=Y_{x 0}+Y_{m 0}^{*}
\end{aligned}
$$




$$
\begin{aligned}
& {\left[\frac{Y \delta}{(1-Y \delta)} C_{0}+\frac{(I-Y)}{R-1} \frac{R}{(R-Y)}\left(Y_{X}-T\right)\right]+\left\{Y \delta^{*} Y_{m O}^{*}\right.} \\
& \left.\quad+\frac{Y}{R-Y}\left(Y_{m}^{*}-T^{*}\right)+\frac{1}{R-I} T^{*}+\left(I+r_{-1}\right) B_{-I}\right] \\
& \left.\quad+\frac{(1-Y)}{R-1} \frac{R}{(R-Y)}\left(Y_{m}^{*}-T^{*}\right)\right\}=\frac{1}{R-1}\left[Y_{X}+Y_{m}^{*}\right]
\end{aligned}
$$

Equation (22) is the reduced-form market-clearing condition for present goods with the left-hand side showing the sum of domestic and foreign private sectors' demands and the right-hand side showing the world supply of outputs net of government spending. Equation (23) is the reduced-form market-clearing condition for future goods with analogous interpretations applied to the terms on its left and righthand sides. These market-clearing conditions are used later in the diagrammatic exposition of the world equilibrium.

Throughout we assume that the foreign government follows a balanced-budget policy and that initially the domestic budget is balanced. This ensures that changes in world rates of interest that result from domestic policies do not impact on the solvency of the foreign government and therefore do not necessitate secondary changes in fiscal policies.

Figure 2 (based on Frenkel and Razin (1986a)) shows the equilibrium of the system. In panel I the PP schedule describes combinations of $R$ and $C_{0}$ that maintain equilibrium in the market for present goods. It is positively sloped since, as seen from equation (22), a fall in the rate of interest raises foreign wealth and induces a rise in foreign spending on present goods; therefore, domestic consumption must fall in order to induce an of setting reduction in demand. The FF schedule describes 
FIGURE 2

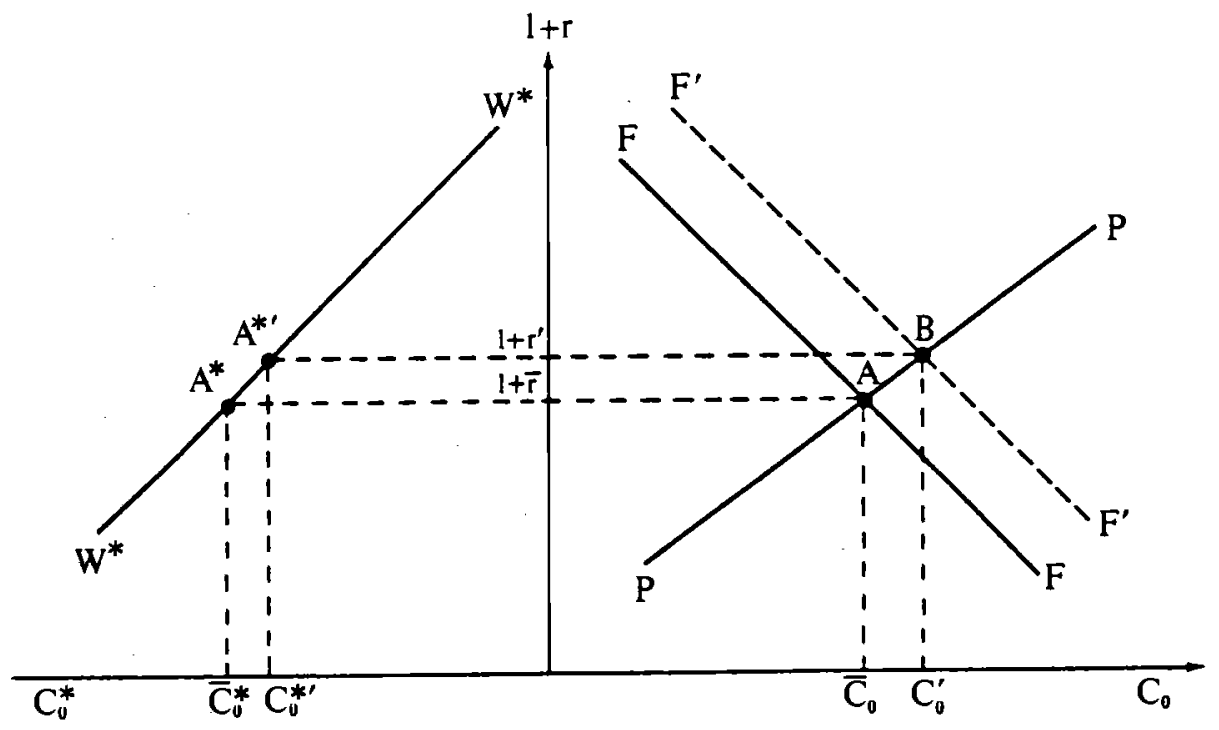


combinations of $\mathrm{R}$ and $\mathrm{C}_{0}$ that maintain equilibrium in the market for future goods. Its slope is negative since a fall in $\mathrm{R}$ creates an excess supply of world future output which is eliminated by an of fsetting rise in demand induced by a rise in domestic wealth that is associated with the rise in $C_{D}$. Panel II of Figure 2 portrays the negatively sloped $W^{*} W^{*}$ schedule describing the equilibrium relationship between $R$ and $C_{0}^{*}$ as implied by the foreign consumption function and by the negative dependence of $\mathrm{W}^{*}$ of $\mathrm{R}$ (from equation (19)). The equilibrium is described by points $A$ and $A^{*}$ at which the values of the variables are $\overline{\mathrm{C}}_{0}, \overline{\mathrm{C}}_{0}^{*}$, and $\overline{\mathrm{R}}$.

If the management of the exchange rate results in domestic-currency overvaluation, then $\mathrm{B}_{0}^{\mathrm{g}}>0$. The presence of this debt necessitates a corresponding $r i s e$ in future taxes by $(R-1) B_{O}^{B}$ according to equation (22). These tax changes do not impact on the PP schedule, but as seen from equation (23) they induce a fall in demand for future goods. To restore equilibrum at the given rate of interest, $W_{0}$ must rise so as to raise demand for future goods. Associated with such a rise in wealth is a rise in current consumption. Thus, the FF schedule shifts to the right. As a result, the new equilibrium is reached at points $\mathrm{B}$ and $\mathrm{B}^{*}$, and $\mathrm{C}_{0}^{\prime}>\overline{\mathrm{C}}_{0}, \mathrm{R}^{\prime}>\overline{\mathrm{R}}$, and $\mathrm{C}_{0}^{{ }^{\prime}}<\overline{\mathrm{C}}_{0}^{*}$. On the other hand, if the management of the exchange rate results in an undervaluation of the domestic currency, the direction of these changes is reversed.

\section{Concluding Remarks}

This paper demonstrated the equivalence between exchange-rate management and tax policies. For this purpose, we used the minimal 
monetary framework and have not attempted to provide a complete analysis of the broader issues associated with monetary and exchange-rate policies in the world economy. To establish the key propositions, we modified the benchmark model characterized by perfect capital markets, flexible market-clearing prices, no distortions, and no difference between the time horizons of the private and the public sector. We showed that dual exchange-rate policies can be usefully viewed as distortionary taxes on international borrowing, and unified pegged exchange-rate policies can be usefully viewed as lump-sum tax cum subsidy policies. The equivalence between the various characteristics of exchange-rate management and tax management justifies the inclusion of exchange-rate analysis into the broader framework of the analysis of fiscal policies. 


\section{Derivation of Equilibrium Wealth}

In this appendix, we derive the equilibrium value of wealth. We first consolidate the periodic budget constraints for the individual. As shown in equation (5), the budget constraint of an individual of age a at time $t$ is:

(A.1) $\quad \bar{e}_{t} P_{t}^{*}{ }^{c} a, t=\bar{e}_{t-1} P_{t-1}^{*} Y_{x}+s_{t} \hat{b}_{a, t}-T_{t}-\left(\frac{\tilde{R}_{F}}{\gamma}\right)_{s_{t}} \hat{b}_{a-1, t-1}$ :

In more detail, these constraints can be written as:

(A.1a) $\quad \vec{e}_{1} P_{0}^{*} c_{a, 0}=\bar{e}_{-1} P_{-1}^{*} Y_{X}+s_{0} \hat{b}_{a 0}-\tilde{T}_{0}-\left(\frac{\tilde{R}_{F}}{\gamma}\right)_{0} \hat{b}_{a-1,-1}$,

(A. ib), $\quad \vec{e}_{1} P_{1}^{*} c_{a+1,1}=\vec{e}_{0} P_{0}^{*} Y_{X}+s_{1} \hat{b}_{a+1,1}-\tilde{T}_{1}-\left(\frac{\tilde{R}_{F}}{\gamma}\right) s_{1} \hat{b}_{a, 0}$,

(A.1c) $\quad \bar{e}_{2} P_{2}^{*} c_{a+2,2}=\bar{e}_{1} P_{1}^{*} Y_{X}+s_{2} \hat{b}_{a+2,2}-\tilde{T}-\left(\frac{\tilde{R}_{F}}{\gamma}\right) s_{2} \hat{b}_{a+1,1}$, etc.

Multiplying equation (A.lc) by $\left(s_{1} / s_{2}\right)\left(\gamma / \vec{R}_{F}\right)$ and adding equation (A.1D) yields:

$$
\text { (A.1d) } \begin{aligned}
\bar{e} P_{1}^{*} c_{a+1,1} & +\frac{\bar{e}_{e} P_{2}^{*} s_{1}}{s_{2}} \frac{\gamma}{\tilde{R}_{F}} c_{a+2,2} \\
& =\bar{e}_{0} P_{0}^{*} Y_{x}+\frac{\bar{e}_{2} P_{2}^{*} s_{1}}{s_{2}} \frac{\gamma}{\tilde{R}_{F}} Y_{x}+s_{1} \frac{\gamma}{\tilde{R}_{F}} \hat{b}_{a+2,2} \\
& -\tilde{T}_{1}-\frac{s_{1}}{s_{2}} \frac{\gamma}{\tilde{R}_{F}} \tilde{T}_{2}-s_{1} \frac{\tilde{R}_{F}}{\gamma} \hat{b}_{a, 0} .
\end{aligned}
$$


Multiplying equation (A.ld) by $\left(s_{0} / s_{1}\right)\left(\gamma / \bar{R}_{F}\right)$, adding to equation (A.la), and dividing the resulting equation by $\bar{e}_{0} P_{0}^{*}$ yields

$$
\begin{aligned}
& \text { (A.1e) } \quad c_{a, 0}+\frac{\bar{e}_{1} P_{1}^{*} s_{0}}{\bar{e}_{0} P_{0}^{*}} \frac{\gamma}{s_{1}} \frac{\gamma}{R_{F}} c_{a+1,1}+\frac{\bar{e}_{2} P_{2}^{*}}{\bar{e}_{0} P_{0}^{*}} \frac{s_{0}}{s_{2}}\left(\frac{\gamma}{R_{F}}\right)^{2} c_{a+2,2} \\
& =\left[\frac{\bar{e}_{-1} P^{*}-1}{\bar{e}_{0} P_{0}^{*}}+\frac{s_{0}}{s_{1}} \frac{\bar{e}_{0} P_{0}^{*}}{\bar{e}_{0} P_{0}^{*}} \frac{y}{\bar{R}_{F}}+\frac{\vec{e}_{1} P_{1}^{*}}{\bar{e}_{0} P_{0}^{*}} \frac{s_{0}}{s_{2}}\left(\frac{Y}{R_{F}}\right)^{2}\right] Y_{X} \\
& +\frac{s_{0}}{\bar{e}_{0} P_{0}^{*}}\left(\frac{\gamma}{R_{F}}\right)^{2} b_{a+2,2} \\
& -\left[\frac{\tilde{T}_{0}}{\bar{e}_{0} P_{0}^{*}}+\frac{s_{0} \tilde{T}_{1}}{s_{1} \bar{e}_{0} P_{0}^{*}}\left(\frac{\gamma}{R_{F}}\right)+\frac{s_{0} \tilde{T}_{2}}{s_{2} \bar{e}_{0} P_{0}^{*}}\left(\frac{\gamma}{R_{F}}\right)^{2}\right] \\
& -\left(\frac{\tilde{R}_{F}}{\gamma}\right) \frac{S_{0}}{\bar{e}_{0} P_{0}^{*}} \hat{b}_{a-1,-1} .
\end{aligned}
$$

Applying a simllar procedure for all periods yields

$(\mathrm{A} .2)$

$$
\begin{aligned}
& \sum_{t=0}^{\infty} \frac{\bar{e}_{t} P_{t}^{*}}{s_{t}} d_{t} c_{a+t, t}=\sum_{t=0}^{\infty} \frac{\bar{e}_{t-1} P_{t-1}^{*}}{s_{t}} d_{t} Y_{X}-\sum_{t=0}^{\infty} d_{t} \frac{\bar{T}_{t}}{s_{t}} \\
& -\left(\frac{\tilde{R}_{F}}{\gamma}\right) \hat{b}_{a-1,1}=\hat{w}_{a 0},
\end{aligned}
$$

where $d_{t}=\left(\gamma / \tilde{R}_{F}\right)^{t}$. Equation (A.2) is equation (6).

To compute the equilibrium value of wealth, we need to incorporate the equilibrium conditions into the expression of wealth in equation (A.2). The monetary mechanism, shown in equations (1) and (2) is reproduced here as 
(A.3) $\quad M_{t}=M_{t-1}+\tilde{X}_{t}-\tilde{T}_{t}$,

(A.4) $\quad \tilde{x}_{t}=\bar{e}_{t} P_{t}^{*}\left(Y_{x}-C_{t}\right)+s_{t}\left(\hat{B}_{t}^{p}-\tilde{R}_{F} \hat{B}_{t-1}^{p}\right)$.

The equilibrium condition is shown by equation (4) and is reproduced here as

(A.5) $\quad M_{t}=\vec{e}_{t} P_{t}^{*} Y^{*}$.

Expressing equation (A.3) as $M_{t-1}-\tilde{T}_{t}=M_{t}-\tilde{x}_{t}$, and using equation (A.5), for $t-1$, we can write equation (A.2) as

(A.6) $\quad \hat{w}_{a 0}=\sum_{t=0}^{\infty} \frac{1}{s_{t}} d_{t}\left(M_{t}-\tilde{x}_{t}\right)-\frac{\tilde{R}_{E}}{\gamma} \hat{b}_{a-1,-1}$.

Finally, using equation (A.5) for $M_{t}$, the equilibrium individual wealth is

$$
\text { (A.7) } \quad \hat{w}_{a 0}=\sum_{t=0}^{\infty} \frac{\bar{e}_{t} P_{t}^{*}}{s_{t}} d_{t} Y_{x}-\sum_{t=0}^{\infty} d_{t} \frac{\tilde{R}_{E}}{s_{t}} \hat{b}_{a-1,-1} \text {. }
$$

To obtain the per-capita value of aggregate wealth, we follow the procedure developed in Frenkel and Razin (1986a). Accordingly, applying the aggregation operator $(1-\gamma) \Sigma_{a=0}^{\infty} \gamma^{a}$ to both sides of equation (A.7), the per-capita wealth, $\hat{w}_{0}$, is

(A.8) $\hat{w}_{0}=\sum_{t=0}^{\infty} \frac{\bar{e}_{t} P_{t}^{*}}{s_{t}} d_{t} Y_{X}-\sum_{t=0}^{\infty} d_{t} \frac{\tilde{X}_{t}}{s_{t}}-\tilde{R}_{F} \hat{B}_{-1}^{p}$.

Using equation (A.4) for $\tilde{X}$ and recalling from the balance of payments accounting that $P_{t}^{*}\left(Y_{X}-C_{t}\right)=-\left(\hat{B}_{t}-\tilde{R}_{F} \hat{B}_{t-1}\right)$, the second term on the right-hand side of equation (A.8) can be written as 


$$
\begin{aligned}
& \text { (A.9) }-t_{t=0}^{\infty} d_{t} \frac{\tilde{x}_{t}}{s_{t}}={ }_{t=0}^{\infty} d_{t} \frac{\bar{e}_{t}\left(\hat{B}-\tilde{R}_{F} \hat{B}_{t-1}\right)-s_{t}\left(\hat{B}_{t}^{p}-\hat{R}_{F} B_{t-1}^{p}\right)}{s_{t}} \\
&=t_{t=0}^{\infty} d_{t} \frac{\bar{e}_{t}}{s_{t}}\left(\hat{B}_{t}-\tilde{R}_{F} B_{t-1}\right)+\tilde{R}_{F,-1} \hat{B}_{-1}^{p}-(1-\gamma){ }_{t=0}^{\infty} d_{t} \hat{B}_{t}^{p} \\
&={ }_{t=0}^{\infty}\left(\frac{\bar{e}_{t}}{s_{t}}-\frac{\bar{e}_{t+1}}{s_{t+1}}\right)_{t} \hat{B}_{t}+\hat{R}_{F,-1} \hat{B}_{-1}^{p} \\
&-(1-\gamma){ }_{t=0}^{\infty} d_{t} \hat{B}_{t}^{p}-\frac{\bar{e}_{0}}{s_{0}} \tilde{R}_{F,-1} \hat{B}_{-1} .
\end{aligned}
$$

Finally, substituting equation (A.9) into equation (A.8) yields:

(A.10) $\quad \hat{W}_{0}=t_{t=0}^{\infty} \frac{\bar{e}_{t} P_{t}^{*}}{s_{t}} d_{t} Y_{X}+\sum_{t=0}^{\infty}\left(\frac{\bar{e}_{t}}{s_{t}}-Y \frac{\bar{e}_{t+1}}{s_{t+1}}\right) d_{t} \hat{B}_{t}$

$$
-(1-\gamma) \sum_{t=0}^{\infty} d_{t} \hat{B}_{t}^{p}-\frac{\bar{e}_{0}}{s_{0}} \tilde{R}_{F,-1} \hat{B}_{-1} \text {. }
$$

which is equation (7). 


\section{References}

Adams, Charles, and Jeremy Greenwood, "Dual Exchange Rate Systems and Capital Controls: An Investigation," Journal of International Economics, Vol. 18 (February 1985), pp. 43-63.

Aizenman, Joshua, "On the Complementarity of Commercial Policy, Capital Controls and Inflation Tax," Canadian Journal of Economics, Vol. 19 (February 1986).

Blanchard, Olivier J., "Debt, Deficits, and Finite Horizors," Journal of Political Economy (April 1985), pp. 223-47.

Dornbusch, Rudiger, "Special Excharge Rates for Capital Account Transactions," World Bank Ecoromic Review, Vol. 1, No. 1 (September 1986), pp. 3-33.

Frenkel, Jacob A., and Assaf Razin (1986a), "Fiscal Policies in the World Economy," Journal of Political Economy, Part 1 (June 1986), pp. 564-94.

(1986b), "The Limited Viability of Dual Exchange-Rate Regimes," NBER Working Paper Series No. 1902 (April 1986).

- Fiscal Policies and the World Economy: An Intertemporal Approach (Boston: MIT Press, 1987).

, "International Effects of Budget Deficits," IMF Staff Papers, 35, No. 2 (June 1988), pp. 297-315.

Greenwood, Jeremy, "Expectations, the Exchange Rate and the Current Account," Journal of Monetary Economics, 12, No. 4 (November 1983), pp. 543-69.

, and Kent Kimbrough, "An Investigation in the Theory of Foreign Exchange Controls," Centre for the Study of International Economic Relations, University of Western Ontario, Working Paper No. 8431 (August 1984).

Helpman, Elhanan, "An Exploration in the Theory of Exchange Rate Regimes," Journal of Political Economy, Vol. 89 (October 1981), pp. $865-90$. , and Assaf Razin, "Towards a Consistent Comparison of Alternative Exchange Rate Regimes," Canadian Journal of Economics, Vol. 12 (August 1979), pp. 374-409.

, "Exchange Rate Management: Intertemporal Tradeoffs," American Economic Review, Vol. 77 (March 1987), pp. 107-23. 
Lucas, Robert E. Jr., "Equilibrium in a Pure Currency Economy," Economic Inquiry, Vol. 18 (June 1980), pp. 203-220. (Reprinted in Models of Monetary Economies, ed. J.H. Kareken and N. Wallace (Minneapolis: Federal Reserve Bank of Minneapolis, 1980), pp. 131-146.)

, "Interest Rates and Currency Prices in a Two-Country World," Journal of Monetary Economics, Vol. 10 (November 1982), pp. 335-59.

Obstfeld, Maurice, "Capital Controls, the Dual Exchange Rate and Devaluation," NBER Working Paper Series No. 1324, April 1984.

Persson, Torsten, "Real Transfers in Fixed Exchange Rate System and the International Adjustment Mechanism," Journal of Monetary Economics, Vo1. 13 (May 1984), pp. 349-69.

, and Lars E.O. Svensson, "International Borrowing and TimeConsistent Fiscal Policy," Scandinavian Journal of Economics, 87 (1985).

Stockman, Alan C., "A Theory of Exchange Rate Determination," Journal of Political Economy, Vol. 86 (August 1980), pp. 673-98.

, and Alejandro D. Hernandez, "Exchange Controls, Capital Controls, and International Financial Markets," NBER Working Paper Series, No. 1755 (October 1985). 